\title{
Outcome Differences between Intra-Arterial Iso- and Low- Osmolality lodinated Radiographic Contrast Media in the Interventional Management of Stroke III Trial
}

T.A. Tomsick, L.D. Foster, D.S. Liebeskind, (DM.D. Hill, J. Carrozella, M. Goyal, R. von Kummer, A.M. Demchuk, I. Dzialowski, V. Puetz, T. Jovin, H. Morales, Y.Y. Palesch, J. Broderick, P. Khatri, and S.D. Yeatts, for the IMS III Investigators

\begin{abstract}
BACKGROUND AND PURPOSE: Intracarotid arterial infusion of nonionic, low-osmolal iohexol contrast medium has been associated with increased intracranial hemorrhage in a rat middle cerebral artery occlusion model compared with saline infusion. Iso-osmolal iodixanol (290 $\mathrm{mOsm} / \mathrm{kg} \mathrm{H}_{2} \mathrm{O}$ ) infusion demonstrated smaller infarcts and less intracranial hemorrhage compared with low-osmolal iopamidol and saline. No studies comparing iodinated radiographic contrast media in human stroke have been performed, to our knowledge. We hypothesized that low-osmolal contrast media may be associated with worse outcomes compared with iodixanol in the Interventional Management of Stroke III Trial (IMS III).
\end{abstract}

MATERIALS AND METHODS: We reviewed prospective iodinated radiographic contrast media data for $133 \mathrm{Ml}$ occlusions treated with endovascular therapy. We compared 5 prespecified efficacy and safety end points (mRS $0-2$ outcome, modified TICl $26-3$ reperfusion, asymptomatic and symptomatic intracranial hemorrhage, and mortality) between those receiving iodixanol ( $n=31)$ or low-osmolal contrast media $(n=102)$. Variables imbalanced between iodinated radiographic contrast media types or associated with outcome were considered potential covariates for the adjusted models. In addition to the iodinated radiographic contrast media type, final covariates were those selected by using the stepwise method in a logistic regression model. Adjusted relative risks were then estimated by using a log-link regression model.

RESULTS: Of baseline or endovascular therapy variables potentially linked to outcome, prior antiplatelet agent use was more common and microcatheter iodinated radiographic contrast media injections were fewer with iodixanol. Relative risk point estimates are in favor of iodixanol for the 5 prespecified end points with Ml occlusion. The percentage of risk differences are numerically greater for microcatheter injections with iodixanol.

CONCLUSIONS: While data favoring the use of iso-osmolal iodixanol for reperfusion of M1 occlusion following IV rtPA are inconclusive, potential pathophysiologic mechanisms suggesting clinical benefit warrant further investigation.

ABBREVIATIONS: EVT = endovascular therapy; IA = intra-arterial; ICH = intracranial hemorrhage; IMS III = Interventional Management of Stroke III Trial; IRCM = iodinated radiographic contrast media; $\mathrm{LOCM}=$ low-osmolal contrast media; $\mathrm{MCl}=$ microcatheter injection; $\mathrm{mTICI}=$ modified TICl; $\mathrm{SICH}=$ symptomatic intracranial hemorrhage

odinated radiographic contrast media (IRCM) have variable antithrombotic, fibrinolytic, cytotoxic, hydrostatic, and vasoactive effects. In a rat middle cerebral artery reperfusion model, intracarotid arterial infusion of the nonionic low-osmolal con-

Received November 19, 2014; accepted after revision March 3, 2015

From the Department of Radiology (T.A.T., J.C., H.M.), University of Cincinnati Academic Health Center, University Hospital, Cincinnati, Ohio; Department of Public Health Sciences (L.D.F., Y.Y.P., S.D.Y.), Medical University of South Carolina, Charleston, South Carolina; University of California, Los Angeles Stroke Center (D.S.L.), Los Angeles, California; Department of Radiology and Clinical Neurosciences (M.D.H., M.G.) and Calgary Stroke Program (A.M.D.), Department of Clinical Neurosciences/Medicine/Community Health Sciences, Hotchkiss Brain Institute, University of Calgary, Calgary, Alberta, Canada; Departments of Neuroradiology (R.v.K.) and Neurology (V.P.), Dresden University Stroke Center, Universitätsklinikum Carl Gustav Carus Technischen Universität Dresden, Dresden, Germany; Department of Neurology (I.D.), Elblandklinikum Meissen, Academic Teaching Hospital of Universitätsklinikum, Carl Gustav Carus Technische Universität Dresden, trast medium (LOCM) iohexol $\left(672 \mathrm{mOsm} / \mathrm{kg} . \mathrm{H}_{2} \mathrm{O}\right)$ increased intracerebral hemorrhage ( $\mathrm{ICH})$ compared with saline infusion. ${ }^{1}$ Iso-osmolal iodixanol $\left(290 \mathrm{mOsm} / \mathrm{kg} \mathrm{H}_{2} \mathrm{O}\right)$ infusion led to

Meißen, Germany; Department of Neurology (J.B., P.K.), University of Cincinnati Academic Health Center, Cincinnati, Ohio; and The Stroke Institute (T.J.), University of Pittsburgh Medical Center, Pittsburgh. Pennsylvania.

This work was supported by grants from the National Institutes of Health and the National Institute of Neurological Disorders and Stroke (UC U01NS052220, MUSC U01NS054630, and U01NS077304) and by Genentech, EKOS, Concentric Medical, Cordis Neurovascular, and Boehringer Ingelheim.

Paper previously presented as a poster abstract at: International Stroke Conference, February 11-13, 2015 Nashville, Tennessee.

Please address correspondence to Thomas A. Tomsick, MD, University of Cincinnati Academic Health Center, UC Health, Department of Radiology, 234 Goodman St, Cincinnati, OH 45267-0761; e-mail: thomas.tomsick@uchealth.com

- Indicates open access to non-subscribers at www.ajnr.org

http://dx.doi.org/10.3174/ajnr.A4421 
Table 1: Baseline clinical characteristics considered for adjusted analysis

\begin{tabular}{|c|c|c|c|}
\hline & lodixanol & LOCM $^{a}$ & $P$ Value \\
\hline $\mathrm{Age}^{\mathrm{b}}$ (median) (range) (yr) & $73(47-83)$ & $68.5(24-82)$ & .07 \\
\hline Baseline glucose ${ }^{b}$ (mmol/L) (median) (range) & $6.9(5.2-18.3)$ & $6.6(3.8-21.5)$ & .33 \\
\hline Diabetes (\%) & 19.4 & 17.7 & .83 \\
\hline Baseline SBP (mm Hg) (median) (range) & $145.5(116-185)$ & $146(102-194)$ & .82 \\
\hline History of high BP (\%) & 74.2 & 73.5 & .94 \\
\hline Atrial fibrillation (\%) & 48.4 & 35.3 & .19 \\
\hline Coronary artery disease (\%) & 35.5 & 19.6 & .07 \\
\hline ASPECTS 8-10 (\%) & 41.9 & 49.0 & .49 \\
\hline \multicolumn{4}{|l|}{ Baseline NIHSS ${ }^{b}$} \\
\hline$\geq 20 \%$ & 35.5 & 37.3 & .86 \\
\hline$\leq 19 \%$ & 64.5 & 62.8 & \\
\hline Historical mRS (No. Sx) ${ }^{\mathrm{b}}(\%)$ & 90.3 & 86.3 & .46 \\
\hline Antiplatelet agents (\%) & 67.7 & 44.1 & .02 \\
\hline Presumptive stroke location right (\%) & 51.6 & 49.0 & .80 \\
\hline Baseline CTA/MRA (\%) & 61.3 & 51.0 & .31 \\
\hline
\end{tabular}

Note:-Sx indicates symptoms; SBP, systolic blood pressure; BP, blood pressure.

${ }^{a}$ Four LOCM (mOsm/ $\mathrm{Kg} \mathrm{H}_{2} \mathrm{O}$ ): iohexol (672), iopamidol (616), ioversol (651), iopromide (607)."

${ }^{\mathrm{b}}$ Baseline factors relevant to prespecified outcomes.

smaller infarcts and less ICH compared with both low-osmolal iopamidol and saline in a similar model. ${ }^{2}$ Dzialowski et $\mathrm{al}^{3}$ reported reduced odds of favorable outcome in patients receiving intravenous IRCM for CT angiography before IV thrombolysis.

Practical differences exist as well: IRCM differ in cost (ie, iodixanol is more expensive than LOCM) and ease of use (ie, iodixanol is more viscous and more difficult to inject). No study has prospectively and comprehensively compared outcomes according to intra-arterial (IA) IRCM use in endovascular therapy (EVT) of ischemic stroke in humans, to our knowledge. We report the efficacy and safety outcomes for subjects with EVT for MCA M1 occlusion in the Interventional Management of Stroke III Trial (IMS III) according to IRCM type and osmolality.

\section{MATERIALS AND METHODS}

Study eligibility/exclusion criteria, methods, and results have been previously reported. ${ }^{4,5}$ Six hundred fifty-six subjects were randomized to either IV rtPA or IV rtPA plus endovascular therapy. CT angiography or MR angiography was not required but was allowed in centers where either was established as a local standard of evaluation and care. Five EVT methods were approved for use during the course of the trial (thrombolysis via standard microcatheter/guidewire rtPA infusion or the EkoSonic Endovascular System [EKOS, Bothell, Washington] $)^{6}$; clot removal via the Merci system (Concentric Medical, Mountain View, California), ${ }^{7,8}$ Penumbra System (Penumbra, Alameda, California), ${ }^{9}$ or Solitaire FR Retriever (Covidien, Irvine, California). ${ }^{10}$ Intra-arterial rtPA infusion was also allowed as an adjuvant to mechanical thrombectomy. A 2000-U bolus of heparin was required per protocol for endovascular treatment procedures, followed by $500-\mathrm{U} / \mathrm{h}$ IV infusion.

The primary outcome measure was a modified Rankin Scale score of $0-2$ at 90 days. Secondary EVT efficacy end points included revascularization, as measured by Modified Thrombolysis in Cerebral Infarction (mTICI) 2-3 and mTICI 2b-3 as ascribed by consensus of the Angiography Core Laboratory members (T.A.T., D.S.L.). Primary safety end points were 90 -day mortality and symptomatic intracranial hemorrhage (SICH) within 30 hours of IV rtPA initiation, defined as an ICH temporally related to a decline in neu- rologic status and new or worsening neurologic symptoms in the judgment of the clinical investigator that may warrant medical intervention. Asymptomatic ICH within 30 hours of IV rtPA initiation was a secondary safety end point.

Investigators prospectively entered data on the IRCM compound type and volume for EVT subjects. The percentage of iodine concentration and/or specific IRCM osmolality was not consistently recorded. Clinical efficacy and safety end points were analyzed for subjects with EVT for M1 occlusion (defined as occlusion of the MCA trunk with 100\% MCA distribution at risk, exclusive of a typical anterior temporal artery distribution), according to EVT use of either isoosmolal iodixanol or any LOCM.

The 2 IRCM groups were initially compared for differences in prescribed outcomes that might warrant further comparative analysis. Baseline risk factors with a potential effect on clinical efficacy or safety outcome in revascularization therapy were then compared for balance between the 2 groups. Baseline variables imbalanced between IRCM types or associated with outcome $(P<.1)$ were considered potential covariates for the adjusted models. Imbalance/association was measured by using the $\chi^{2}$, Fisher, or Wilcoxon 2-sample test, as appropriate. The linearity in the logit assumption was checked for all continuous potential covariates. In addition to IRCM type, final covariates were those selected by using the stepwise method in a logistic regression model. Model fit was assessed via the Hosmer-Lemeshow test. For ease of interpretation, adjusted relative risks were then estimated by using a log-link regression model.

\section{RESULTS}

Thirty-one M1 occlusions were treated with iodixanol use during EVT, and 102, with LOCM of 4 different types. Differences in baseline characteristics known to be relevant in stroke efficacy or safety outcome with revascularization therapy and other relevant treatment-related variables are included in Tables 1 and 2.

Table 3 details relative and absolute efficacy and safety differences between the 2 IRCM groups.

Separate adjusted models were fit for each outcome (except $\mathrm{SICH}$, due to an insufficient event rate). Variables imbalanced between IRCM types or associated with outcome $(P<.1)$ were considered potential covariates for the adjusted models, including antiplatelet medication (67.7\% iodixanol versus $44.1 \%$, $P=.0212)$, history of coronary artery disease $(35.5 \%$ iodixanol versus $19.6 \%, P=.0671$ ), age (iodixanol median, 73 versus 68.5 years, $P=.0698)$, and microcatheter injection (MCI) (median, 1 iodixanol versus $2 \mathrm{LOCM} P=.03$ ), varied according to IRCM type.

Adjusted relative risk point estimates were in favor of the iodixanol group for all outcomes (Table 4). No significant differences for specified outcomes were identified. Conclusions remained the same after sensitivity analyses were performed for asymptomatic ICH and 
mRS 0-2 outcome models to include adjustments for variables known to be associated with these outcomes.

As a known variable affecting procedure outcome that was unequally distributed, MCIs were further analyzed. In bivariate analysis of MCI number compared with outcomes independent of the IRCM group, significant relationships were identified. Fewer MCIs were associated with greater mRS $0-2$ outcome $(P=$ $.029)$ and better reperfusion $(P=.003)$. MCI remained a significant predictor of reperfusion when adjusted for key baseline and treatment-related variables. MCIs were not significant predictors of mRS $0-2$ or mortality when adjusted for other key variables. Ninety-one of 133 (68.5\%) subjects had MCIs, including 16/31 $(52 \%)$ with iodixanol and $75 / 102(73.5 \%)$ with LOCM $(P=$ $.022)$. With MCI use, percentage risk differences in the measured end points were in favor of iodixanol for all end points. MCI use did not differ among device methods.

\section{DISCUSSION}

The potential risks and safety of IRCM use in the setting of acute stroke in humans have been discussed for a long time, with the advantages in diagnosis and treatment assumed to outweigh any theoretic, unproven risks. ${ }^{11,12}$ However, with effective ischemic stroke therapies now available, investigation and deeper understanding of the theoretic effects of different media may assume greater practical significance.

Our analyses here disclose potential differences in outcomes from stroke treatment arising from the use of IA iso-

Table 2: Relevant treatment-related variables considered for adjusted analysis

\begin{tabular}{lccc}
\hline & lodixanol & LOCM $^{\mathbf{a}}$ & $\boldsymbol{P}$ Value \\
\hline Time to IV therapy (min) (median) & 124 & 115 & .25 \\
Onset to puncture (min) (median) & 215 & 205 & .29 \\
Proximal Ml (vs distal) (\%) & 45.2 & 52.0 & .51 \\
Thrombolysis only (\%) & 41.9 & 36.2 & .57 \\
No. microcatheter injections (median) & 1 & 2 & .03 \\
Heparin volume (U) (median) & 3185 & 2986.8 & .59 \\
New emboli (\%) & 16.1 & 11.8 & .54 \\
IRCM volume (mL) (median) & 85 & 64 & .34 \\
Infarct volume $24 \mathrm{hr}(\mathrm{mL})^{\mathrm{a}}$ (median) & 61.0 & 50.2 & .23 \\
\hline
\end{tabular}

${ }^{a}$ Four LOCM (mOsm/Kg H2O): iohexol (672), iopamidol (616), ioversol (651), iopromide (607)."

Table 3: Efficacy and safety outcomes according to iodixanol versus LOCM use

\begin{tabular}{lcccc}
\hline & $\begin{array}{c}\text { lodixanol } \\
\text { (No.) (\%) }\end{array}$ & $\begin{array}{c}\text { LOCM } \\
\text { (No.) (\%) }\end{array}$ & $\begin{array}{c}\text { Absolute \% Risk } \\
\text { Difference }\end{array}$ & $\begin{array}{r}\text { Relative \% } \\
\text { Difference }\end{array}$ \\
\hline $\mathrm{N}$ & 31 & 102 & - & - \\
$\mathrm{mTICl} \mathrm{2b/3}$ & $16(51.6)$ & $42(41.2)$ & 10.4 & 20.2 \\
$\mathrm{mRS} \mathrm{0-2}$ & $11(35.5)$ & $31(30.4)$ & 5.1 & 14.4 \\
$\mathrm{AICH}$ & $9(29.0)$ & $42(41.2)$ & -12.1 & -29.6 \\
$\mathrm{SICH}$ & $2(6.5)$ & $9(8.8)$ & -2.4 & -26.1 \\
Mortality & $6(19.4)$ & $26(25.5)$ & -6.1 & -23.9 \\
\hline
\end{tabular}

Note:-AICH indicates asymptomatic ICH.

Table 4: Relative risk of specified outcomes for iodixanol versus LOCM

\begin{tabular}{lcccccc}
\hline & \multicolumn{3}{c}{ Unadjusted } & & \multicolumn{3}{c}{ Adjusted } \\
\cline { 2 - 4 } & RR & & $\mathbf{9 9 \%} \mathrm{Cl}$ & & $\mathbf{R R}$ & $\mathbf{9 9 \%} \mathrm{Cl}$ \\
\hline $\mathrm{mRS} \mathrm{0-2}$ & 1.1675 & 0.5606 & 2.4314 & 1.2002 & 0.6123 & 2.3528 \\
$\mathrm{mTICl} 2 \mathrm{~b} / 3$ & 1.2535 & 0.7291 & 2.1549 & 1.2829 & 0.7888 & 2.0864 \\
$\mathrm{AICH}$ & 0.7051 & 0.3216 & 1.5457 & 0.6596 & 0.3051 & $\mathrm{NA}$ \\
$\mathrm{SICH}$ & 0.7312 & 0.1048 & 5.1038 & & 0.4260 \\
Mortality & 0.7593 & 0.2683 & 2.1486 & 0.7538 & 0.2767 & 2.0537 \\
\hline
\end{tabular}

Note:-RR indicates relative risk; $\mathrm{AICH}$, asymptomatic ICH. osmolal iodixanol versus LOCM agents for EVT following IV rtPA in the setting of microcatheter use. Raw, unadjusted, and adjusted directions of effect were in favor of iodixanol for all prespecified efficacy and safety outcomes. Relatively greater age, blood glucose, percentage of atrial fibrillation, and CT hypoattenuation (as manifested by a lower ASPECT score), followed by relatively later IV rtPA administration, longer time to artery puncture, and more thrombolysis-only procedures, were present in the iodixanol group. Prior antiplatelet use, the only baseline variable significantly greater with iodixanol, has been associated with a small excess of SICH in systemic thrombolytic therapy. ${ }^{13}$ While these factors should disadvantage iodixanol regarding mRS $0-2$ outcome and ICH rate, point estimates from adjusted analyses remain in favor of iodixanol. MCIs were less common in the iodixanol group. Procedures with no MCI showed no benefit to iodixanol use. When MCIs were analyzed according to IRCM use, however, a greater relative benefit was suggested with MCI iodixanol use compared with LOCM for all end points.

IRCM effects may be collectively related to their ionic or nonionic properties, iso-osmolality, and their molecular structure and size as monomers or dimers. Osmolality is, in part, related to iodine concentration, generally recommended at 300-mg per cent for cerebral use. Multiple iodine concentrations of the same IRCM compound type were used in IMS III. Consensus that the use of ionic high-osmolal IRCM was associated with worse outcome after infarction in humans and animals has eliminated their use in this setting. ${ }^{11,12,14}$ LOCM nonionic media may contribute to ICH in animals. ${ }^{1}$ Differences in ICH number and infarct area effects might also exist between injection of iso-osmolal and LOCM. ${ }^{2}$ It is reasonable to further hypothesize, then, that nonionic iso-osmolal IRCM may have a less harmful net effect in the setting of acute stroke than nonionic LOCM. No comparative data in IV or IA IRCM use in human stroke are available to refute that hypothesis. ${ }^{3}$

Mechanisms contributing to potential differences in IRCM efficacy and safety have been extensively analyzed under a variety of experimental conditions in vitro and in animal models, including coagulation, direct cytotoxic, neurotoxic, osmotic, hydrostatic, and direct vasomotor effects. 


\section{Coagulation}

Platelet Activity Effects. Direct activation of platelets (ie, degranulation and release of the procoagulant content of attenuated bodies and $\alpha$-granules) is induced in vitro by nonionic LOCM, with no activation by LOCM ionic (eg, ioxaglate) and nonionic dimeric iodixanol. ${ }^{15-17}$ Nonionic iohexol and iodixanol are equivalent in reducing platelet aggregation. ${ }^{18,19}$ In vitro platelet activation by thrombin is inhibited by ionic LOCM, whereas nonionic monomeric LOCM and dimeric iodixanol did not affect it. ${ }^{20}$ Prior antiplatelet use of aspirin conferred neither clinical nor reperfusion benefit nor hemorrhagic risk in conjunction with IV rtPA in the National Institute of Neurological Disorders and Stroke trial, and none has previously been demonstrated in EVT. ${ }^{21,22}$ While antiplatelet use in IMS III tended to be associated with increased ICH overall, its use was more common in the iodixanol group, yet ICH was decreased with iodixanol use.

Thrombin Activity Effects. The heparin dose used during EVT did not differ between the 2 treatment groups. Nonionic agents cause less direct inhibition of thrombin production compared with ionic IRCM, acting after the generation of thrombin at the step of fibrin monomer polymerization. ${ }^{23}$ Both ionic and nonionic agents can prolong clotting time and may exaggerate the effects of anticoagulant and antiplatelet drugs. ${ }^{24}$ Nonionic LOCM iopamidol and iohexol have an anticoagulant effect but permit thrombin generation in vitro. ${ }^{25-27}$ The anticoagulant effect of iodixanol has been shown to be significantly less than that of iohexol. ${ }^{16}$ LOCM iopamidol has been found to have a greater thrombotic effect than iodixanol. ${ }^{28}$ One of 3 clinical studies of coronary intervention found a significant decrease in abrupt vessel occlusions with iodixanol, particularly in the absence of glycoprotein IIb/IIIa blockers, while the other 2 found no differences in major cardiac events. ${ }^{29}$ No differences in mortality or length of stay were found among 107,994 coronary angiographies or interventions with 3 different LOCM. ${ }^{29}$ Outcome differences in IRCM effects between procedures performed for acute occlusive EVT have been suggested for coronary intervention yet have also been inconclusive due to limited power. ${ }^{30}$

Fibrinolytic Effects. IRCM delay and impede fibrinolysis by recombinant tissue-type plasminogen activator. In vitro studies have shown that while iohexol delays the onset of lysis induced by all lytic agents, ioxaglate delayed the onset of lysis by rtPA and urokinase but not by streptokinase. ${ }^{31}$ In vivo studies in dogs have shown that alteplase-induced fibrinolysis could be inhibited by iohexol. Reocclusion of coronary arteries following fibrinolysis was more common after IRCM administration, despite concomitant aspirin and heparin therapy. ${ }^{32}$ Iohexol has been demonstrated to increase plasma levels of tPA plasminogen activator inhibitor type 1 in patients undergoing pulmonary angiography. ${ }^{33}$ In an in vitro model of the sonographic effect on fibrinolysis, very limited data suggested that iodixanol may diminish the rate of sonography-assisted thrombus dissolution. ${ }^{34}$ While a meta-analysis investigating the fibrinolysis effect of IRCM of any type or route of administration (IV or IA) has suggested no difference in recanalization rates, ${ }^{35}$ the wide range of fibrinolytic practices makes the study only marginally relevant to the potential effects of individual IRCM types with EVT of M1 occlusion in
IMS III. Dzialowski et $\mathrm{al}^{3}$ reported reduced odds of favorable outcome in patients receiving IV contrast for CT angiography before IV thrombolysis.

Cytotoxic and Osmotic Effects. Cytotoxic effects on endothelial cells may contribute to thrombosis. While no clinically significant differences among nonionic IRCM are confirmed, buckling of endothelial cells with alteration of function is less conspicuous with iodixanol. ${ }^{36,37}$ IRCM can also induce apoptosis of endothelial cells in vitro. ${ }^{38}$ Significant in vitro differences between IRCM on red blood cell count morphology may also contribute to thrombosis in vivo, with iodixanol retaining a greater percentage of normal morphology compared with LOCM agents. ${ }^{39}$

Both IV and IA IRCM injection increase the permeability of the blood-brain barrier under normal conditions in animals. ${ }^{40-42}$ Osmolality plays an important role in the BBB dysfunction, particularly after ischemic injury, even contributing to larger infarcts with hyperosmolal compared with iso-osmolal IRCM infusion. ${ }^{12}$ Hypertension, which may reflexly occur with arterial occlusion, potentiates the effect of these BBB effects. ${ }^{43}$ In humans, IRCM identification in the brain or subarachnoid space after aneurysm coiling procedures by using large IRCM volumes is usually asymptomatic. $^{44,45}$ Theoretically, it is possible that large IV or IA doses of IRCM (as used in nonischemia EVT procedures) may contribute to exaggerated BBB opening, edema, IRCM deposition, and ICH in ischemic stroke EVT as well. ${ }^{46,47}$

Following acute ischemia in rats, early leakage of MR imaging contrast agents across the BBB has been shown to predict and co-localize to subsequent hemorrhagic transformation. ${ }^{48,49}$ In humans, contrast media deposition during MR imaging and CT perfusion in the acute ischemic setting is also a marker of subsequent hemorrhagic transformation. ${ }^{50-52}$ Depositions confirmed on both post-EVT CT and MR imaging have also co-localized to MR imaging contrast enhancement and hemorrhagic transformation. ${ }^{53} \mathrm{MR}$ imaging contrast deposition during routine gadolinium-enhanced MR imaging following IV rtPA occurs in approximately $20 \%$ of infarcts and is predictive of subsequent ICH. ${ }^{54,55}$ Lummul et al ${ }^{56}$ connected CT-hyperattenuated cerebral lesions with IRCM deposition following both CTA/CTP and subsequent EVT. The high incidence of hyperattenuated lesions and the percentage of secondary ICH suggest that they both may be IRCM-volume related. It remains unclear whether contrast media deposition is both effect and cause, with IRCM leaking across the $\mathrm{BBB}$ contributing to additive cytotoxic effects on the interstitium and neuronal elements. However, in IMS III, the median iodixanol volume was numerically higher than that for LOCM, suggesting that either worse measured outcome differences were not merely LOCM-volume-related or greater iodixanol volume exerted a protective effect.

Complex mechanisms beyond osmolality-related toxicity and dysfunction may be operative. ${ }^{57,58}$ Heinrich et $\mathrm{al}^{59}$ compared the cytotoxic effects of dimeric iso-osmolal IRCM (iodixanol, iotrolan) and iso-osmolal formulations of monomeric IRCM on renal tubular cells in vitro and found that dimeric IRCM have stronger cytotoxic effects, postulating a mechanism beyond osmolality alone. Molecular chemotoxicity decreases as the number of carboxyl groups decreases and the number of hydroxyl groups increases, and IRCM with no carboxyl groups and a number of 
hydroxyl groups evenly distributed around the main molecule have reduced neurotoxicity. ${ }^{60,61}$ Iodixanol has an increased number of hydroxyl groups $(n=9)$ compared with LOCM (eg, 5 for iopamidol), but more carboxy groups (6 versus 3 ), theoretically disadvantageous in human use. Increasing the number of hydroxyl groups also increases solubility, thus reducing the tendency to bind to tissues and proteins, which may then lead to inhibition of enzyme systems, including acetylcholinesterase. ${ }^{62,63}$ The net vector for the benefit of the complex structural arrangement of iodixanol is uncertain.

Hyperosmolality-toxicity injury may be offset, in part, by a beneficial osmotic tonicity effect of intravascular IRCM on the intravascular and extracellular spaces based on molecular size. Dimeric iodixanol $(1000 \mathrm{Da})$ is approximately twice as large as monomeric iopamidol (550 Da). Five times larger than mannitol (182 Da), iodixanol may not only be less able to traverse early damage to the $\mathrm{BBB}$ to exert adverse direct toxic or osmotic effects beyond endothelial cell tight junctions in the basal lamina or in the extracellular space, but it also may offer a microvascular osmotic advantage. ${ }^{64}$ Conversely, monomeric LOCM may ultimately more easily traverse the damaged membrane to promote increased edema by an osmotic tissue effect. While conflicting evidence regarding increased neurotoxicity once the IRCM has crossed the BBB in animals and humans exists, ${ }^{12,14,65-68}$ an additive effect of IRCM traversing the damaged BBB into the interstitium, affecting cellular and neural elements, contributing to greater ICH potential and neural injury, is hypothesized.

Hydrostatic Effects. Viscosity differences (iodixanol $11.8 \mathrm{cP}$ at $37^{\circ}$ versus iopamidol $4.7 \mathrm{cP}$ ) may simultaneously lead to a reduced hydrostatic effect of viscous, dimeric iodixanol, with prolonged vascular retention at the injured $\mathrm{BBB}$, and may contribute to the reduced infarct edema volume measured in rats. ${ }^{69}$ Hydrolysis of iodixanol in vitro can produce a derivative of propylene glycol (2,3-dihydroxy-1-propylamine $\mathrm{HOCH} 2-\mathrm{CH}[\mathrm{OH}]-\mathrm{CH} 2-$ $\mathrm{NH} 2$ ), which, when injected intra-arterially in a rat ischemia model, has been found to decrease BBB dysfunction by a "sealing" effect, with subsequent decreased permeability and infarct size. ${ }^{70}$ Similar hydrostatic IA "sealing" effects on the BBB could even be possible under certain conditions. ${ }^{71,72}$ Molecule size alone may present a relative microvascular seal, delaying not only early ionic edema but also diminishing later vasogenic edema associated with hemorrhagic transformation.

Relatively reduced asymptomatic ICH and SICH with iodixanol in IMS III, despite the possibility of better mTICI reperfusion and larger infarct volume, contradict the theoretic construct of reperfusion $\mathrm{ICH}$ effects, suggesting that iodixanol may somehow offer an unrelated protective effect against $\mathrm{ICH}{ }^{73}$ The mechanism of hemorrhagic transformation, though linked to reperfusion, infarct volume, and edema, might have a separate and different pathophysiologic pathway after reperfusion of acute ischemic stroke in humans and animals. ${ }^{74,75}$ Infarct size and ICH differences are greater in rats with temporary-versus-permanent MCA occlusion. ${ }^{76}$ Reduced infarct edema volume as a measure of reduced reperfusion injury with both LOCM-versus-saline reperfusion and viscous iso-osmolal-versus-less viscous LOCM has been found in rats. ${ }^{1,2}$ In humans, improved mTICI reperfusion following ischemia would be anticipated to increase levels of re- active oxygen species, including superoxide radical and nitric oxide. $^{77,78}$ Oxidative radicals trigger activation of metalloproteinases, which, in turn, potentiate injury to microvasculature and neural cells. ${ }^{79,80}$ However, IRCM may decrease the endothelial production of nitric oxide by reducing the activity of the enzyme nitric oxide synthase, which is responsible for the endogenous synthesis of this vasodilator. ${ }^{81,82}$ Variable vasoactive effects of IRCM have been identified in the renal vasculature, where both iopamidol and iodixanol caused a brief initial vasodilation, followed by increased resistance with iopamidol, but not iodixanol. ${ }^{83}$ Increased $\mathrm{CO}_{2}$ release from the rat hippocampus incubated with the iso-osmolar dimers iotrolan and iodixanol has been measured, a potentiator of vasodilation. Increased $\mathrm{CO}_{2}$ production could involve an effect of the glucose metabolic pathway or be indirect via an unspecified mechanism that increases cell glucose use. ${ }^{84}$ Potential glucose metabolism effects of IRCM have been identified in vitro and in vivo for metrizamide, but not for iohexol or iopamidol. Clinically significant vasomotor differences in the cerebral vasculature in humans are unknown.

Miscellaneous Effects. IRCM have been reported to adversely affect oxyhemoglobin dissociation. ${ }^{85}$ Decreased $\mathrm{pH}$ or increased temperature in the hypoxic brain tissue can cause changes in the physicochemical properties of IRCM as well. Increased BBB disruption has been demonstrated in rabbits with IA injection of higher iodine-concentration IRCM (300 versus $150 \mathrm{mg} / \mathrm{mL}$ ), at a lower temperature $\left(24^{\circ} \mathrm{C}\right.$ versus $\left.37^{\circ} \mathrm{C}\right)$, during a briefer time $(1$ versus 30 seconds). ${ }^{86}$ The role that these miscellaneous effects might play in EVT can only be theorized.

ICH has been previously linked to microcatheter IRCM injections during EVT. ${ }^{67,87}$ Microcatheter IRCM injections push saline ahead at higher initial pressures and flow rates, which decrease as the catheter becomes IRCM-filled (D. Hansmann, EKOS, unpublished data, 2014). The viscosity of iodixanol may diminish such distal catheter pressure and flow effects compared with LOCM, and it offers a relative safety margin reflected in lower ICH and SICH rates. Microcatheter IRCM injection delivers a higher concentration of IRCM locally within the occlusion, which then may wash out more slowly from patent or partially obstructed microvasculature, thereby amplifying protective hydrostatic microvascular iodixanol effects. Local microcatheter saline injections, used to clear catheters of IRCM, with pressure and flow increasing through the act of clearance, may be equally responsible for any untoward effects of IRCM MCI.

There are limitations to our results, analysis, and hypotheses. First, the importance of an unrecognized baseline or treatment factor may be underestimated. Prior antiplatelet and iodixanol use may favor revascularization and clinical outcomes in a way not previously demonstrated in IV or EVT revascularization studies. The specifics of recording IA injections of IRCM in a revascularization procedure leave room for wide ranges of practice variables that theoretically may have a secondary effect on outcome. Injections such as hand or power, intracranial microcatheter or cervical guide, saline-diluted or full-strength, high- or low-pressure, large- or low-volume may all be performed during the same procedure. Differences among operators that almost assuredly exist in all these variables may become relatively reproducible 
within a the practice of a single operator or center. Site variables, then, might affect outcomes.

LOCM use following IV rtPA may not have the same effects by comparison in the absence of IV rtPA. While the impact of any proved, actionable differences between IRCM may be diminished in the current EVT atmosphere of shorter procedures with reduced IRCM volume use with application of devices not studied in IMS III, the use of MCI with LOCM may still prove to be a relevant risk factor.

While this is an analysis of a homogeneous population of M1 occlusion, new emboli during treatment in previously uninvolved vessels occurred in $12.8 \%$ of subjects with M1 occlusion in IMS III, numerically more common in the iodixanol group $(16.1 \%$ versus $11.8 \%$ ). An estimated $13 \%$ difference in mRS $0-2$ outcomes between subjects with and without new emboli in IMS III has been reported. ${ }^{4}$ While new emboli may have contributed to nonsignificantly larger infarcts in the iodixanol group, it remains unclear how larger infarcts relate to better clinical outcome.

\section{CONCLUSIONS}

A potential protective effect of iodixanol use in the EVT of M1 occlusion is proposed in IMS III, but perhaps only in the setting of MCI. Iodixanol contributes less endothelial cytotoxic effect to the thrombotic process. Its lower anticoagulant effect may diminish hemorrhagic transformation, with numerically fewer SICHs and fewer asymptomatic ICHs despite greater prior antiplatelet use. Its passage across the $\mathrm{BBB}$ is less than that with LOCM, while retaining a favorable osmotic microvascular potential. It may also have beneficial hydrostatic and vasoactive activity. The hypothesis that a small difference in outcomes may indeed exist by using different IRCM remains unproven in a small study population with only $50 \%$ of subjects with major arterial occlusion predisposed to good outcome. ${ }^{88}$ Further analysis of not only the magnitude of the clinical effect potential of isosmolal IRCM but also the mechanisms conferring such benefit is warranted.

Disclosures: Thomas A. Tomsick—RELATED: Grant: University of Cincinnati, ${ }^{*}$ Comments: Co-Principal Investigator, Principal Interventionist, IMS III; Angiographic Core Laboratory IMS III; Support for Travel to Meetings for the Study or Other Purposes: Executive Committee Meeting, Scientific Meeting travel expenses reimbursed through an IMS III grant; UNRELATED: Expert Testimony: consult and give expert testimony on stroke imaging or treatment-related cases (multiple law offices). Lydia D. Foster-RELATED: Grant: National Institute of Neurological Disorders and Stroke.* Ruediger von Kummer-RELATED: Support for Travel to Meetings for the Study or Other Purposes: National Institutes of Health, Comments: travel to meetings of the IMS III executive committee; Board Membership: Lundbeck; Consultancy: Lundbeck, Penumbra, Covidien, Boehringer Ingelheim; Payment for Lectures (including service on Speakers Bureaus): Penumbra. Mayank Goyal—UNRELATED: Consultancy: Covidien, Comments: for trial design and conduct of Solitaire With the Intention For Thrombectomy as PRIMary Endovascular Treatment trial and for teaching engagements; Grants/Grants Pending: Covidien, ${ }^{*}$ Comments: institutional grant for partial funding for Evaluation Study of Congestive Heart Failure and Pulmonary Artery Catheterization Effectiveness trial; Payment for Lectures (including service on Speakers Bureaus): Covidien, Comments: for speaking engagements and teaching. Imanuel Dzialowski-RELATED: Support for Travel to Meetings for the Study or Other Purposes: honoraria for physician scientific advisory activity for the IMS III study. Yuko Y. Palesch—RELATED: Grant: National Institutes of Health,* Comments: for the IMS III trial; Support for Travel to Meetings for the Study or Other Purposes: National Institutes of Health, ${ }^{*}$ Comments: for travel related to the IMS III grant activities and presentations at conferences; UNRELATED: Consultancy: Brainsgate, Biogen, Comments: honorarium for Data Monitoring Committee statistical member; Grants/Grants Pending: National Institutes of Health, ${ }^{*}$ Comments: $\mathrm{U} 01$ and R01 grants; Travel/Accommodations/Meeting Expenses Unrelated to Activities Listed: Brainsgate, Comments: travel reimbursement for a Data Monitoring
Committee meeting. Pooja Khatri—RELATED: Grant: National Institutes of Health IMS III trial grant*; UNRELATED: Other: Genentech,* Penumbra, ${ }^{*}$ Biogen, ${ }^{*}$ Comments: Each pay my institutional department for my research roles in trials: Genentech/Study of Efficacy and Safety of Activase in Patients with Mild Stroke (PRISMS), Lead Principal Investigator, Penumbra/Assess the Penumbra System in the Treatment of Acute Stroke Trial, Neuro Principal Investigator, Biogen/Data Safety Monitoring Board member. Joseph Broderick—RELATED: Grant: Genentech, ${ }^{\star}$ Comments: For PRISMS study; Other: Genenetech, ${ }^{*}$ Concentric, ${ }^{*}$ EKOS, ${ }^{\star}$ Cordis Neurovascular, * Comments: study medication for IMS III, Concentric, EKOS, Cordis Neurovascular; catheters for study in early years of IMS III; UNRELATED: Travel/Accommodations/ Meeting Expenses Unrelated to Activities Listed: Boehringer Ingelheim, Comments: paid for travel to International Meeting where I was keynote speaker. Sharon D. Yeatts—RELATED: Grant: National Institute of Neurological Disorders and Stroke, * Comments: grant support for unblinded statistical role on IMS III; UNRELATED: Consultancy: Genentech, Comments: statistician member of PRISMS Trial Steering Committee; Expert Testimony: National Institute of Neurological Disorders and Stroke, * Comments: statistical involvement in Albumin in Acute Stroke, Hi-dose Deferoxamine in Intracerebral Hemorrhage/Intracerebral Hemorrhage Deferoxamine clinical trials. Andrew M. Demchuk-RELATED: Grant: National Institutes of Health,* Comments: CT core laboratory funding for IMS III; UNRELATED: Grants/Grants Pending: Covidien, ${ }^{*}$ Comments: unrestricted grant to support Evaluation Study of Congestive Heart Failure and Pulmonary Artery Catheterization Effectiveness trial; Payment for Lectures (including service on Speakers Bureaus): Covidien, Comments: speaker fees for Continuing Medical Education events. Janice Carrozella—RELATED: Grant: National Institutes of Health/National Institute of Neurological Disorders and Stroke, ${ }^{*}$ Comments: IMS III trial. Michael D. Hill—UNRELATED: Board Membership: Heart and Stroke Foundation of Alberta/NWT and Nunavut (Board Member: 2010-12; Vice-Chairman: 2012-2014; Chairman); Institute for Circulatory and Respiratory Health of Canadian Institutes of Health Research (Advisory Board: 2009-2013); Canadian Federation of Neurological Sciences (Advisory Board: 2013-2016); Consultancy: Vernalis Group (2009); Merck, Adjudication Committee for Diabetes clinical trials (2014-present); Grants/Grants Pending: Hoffmann-La Roche Canada (2011-2013, provided drug for clinical trial), ${ }^{*}$ Covidien (2013-2014, grant for a clinical trial)*; Payment for Lectures (including service on Speakers Bureaus): Hoffmann-LaRoche Canada (2009, consultancy and Continuing Medical Education lecture), ${ }^{*}$ Servier Canada (2012 Continuing Medical Education lecture, funds donated to charity), * Bristol-Myers Squibb Canada (2012, consultancy, fund donated to charity); Stock/Stock Options: Calgary Scientific, Comments: technology software company in imaging; Other: Heart and Stroke Foundation of Alberta/NWT and Nunavut (salary award 2012-2015), * Albert Innovates-Health Solutions (salary award 2009-2014). * *Money paid to the institution.

\section{REFERENCES}

1. Kurosawa Y, Lu A, Khatri P, et al. Intra-arterial iodinated radiographic contrast material injection administration in a rat middle cerebral artery occlusion and reperfusion model: possible effects on intracerebral hemorrhage. Stroke 2010;41:1013-17 CrossRef Medline

2. Morales H, Lu A, Kurosawa Y, et al. Decreased infarct volume and intracranial hemorrhage associated with intra-arterial nonionic iso-osmolar contrast material in an MCA occlusion/reperfusion model. AJNR Am J Neuroradiol 2014;35:1885-91 CrossRef Medline

3. Dzialowski I, Puetz V, Buchan AM, et al; Calgary Stroke Program. Does the application of $x$-ray contrast agents impair the clinical effect of intravenous recombinant tissue-type plasminogen activator in acute ischemic stroke patients? Stroke 2012;43:1567-71 CrossRef Medline

4. Broderick JP, Palesch YY, Demchuk AM, et al; Interventional Management of Stroke (IMS) III Investigators. Endovascular therapy after intravenous t-PA versus t-PA alone for stroke. $N$ Engl J Med 2013;368:893-903 CrossRef Medline

5. Khatri P, Hill M, Palesch Y, et al; Interventional Management of Stroke III Investigators. Methodology of the Interventional Management of Stroke III Trial. Int J Stroke 2008;3:130-37 CrossRef Medline

6. Tomsick T, Broderick J, Carrozella J, et al; IMS II Investigators. Revascularization results in the Interventional Management of Stroke II trial. AJNR Am J Neuroradiol 2008;29:582-87 CrossRef Medline

7. Smith WS, Sung G, Starkman S, et al; MERCI Trial Investigators. Safety and efficacy of mechanical embolectomy in acute ischemic stroke: results of the MERCI trial. Stroke 2005;36:1432-38 CrossRef Medline

8. Smith WS, Sung G, Saver J, et al. Mechanical thrombectomy for 
acute ischemic stroke: final results of the Multi MERCI trial. Stroke 2008;39:1205-12 CrossRef Medline

9. Penumbra Pivotal Stroke Trial Investigators. The Penumbra Pivotal Stroke Trial: safety and effectiveness of a new generation of mechanical devices for clot removal in intracranial large vessel occlusive disease. Stroke 2009;40:2761-68 CrossRef Medline

10. Dávalos A, Pereira VM, Chapot R, et al; Solitaire Group. Retrospective multicenter study of Solitaire FR for revascularization in the treatment of acute ischemic stroke. Stroke 2012;43:2699-705 CrossRef Medline

11. Kendall BE, Pullicino P. Intravascular contrast injection in ischaemic lesions, II: effect on prognosis. Neuroradiology 1980;19: 241-43 Medline

12. Doerfler A, Engelhorn T, von Kummer R, et al. Are iodinated contrast agents detrimental in acute cerebral ischemia? An experimental study in rats. Radiology 1998;206:211-17 CrossRef Medline

13. Diedler J, Ahmed N, Sykora M, et al. Safety of intravenous thrombolysis for acute ischemic stroke in patients receiving antiplatelet therapy at stroke onset. Stroke 2010;41:288-94 CrossRef Medline

14. Hayman LA, Evans RA, Bastion FO, et al. Delayed high dose contrast $\mathrm{CT}$ : identifying patients at risk of massive hemorrhagic infarction. AJR Am J Roentgenol 1981;136:1151-59 CrossRef Medline

15. Chronos NA, Goodall AH, Wilson DJ, et al. Profound platelet degranulation is an important side effect of some types of contrast media used in interventional cardiology. Circulation 1993;88: 2035-44 CrossRef Medline

16. Corot C, Chronos N, Sabattier V. In vitro comparison of the effects of contrast media on coagulation and platelet activation. Blood Coagul Fibrinolysis 1996;7:602-08 CrossRef Medline

17. Jones CI, Goodall AH. Differential effects of the iodinated contrast agents Ioxaglate, Iohexol and Iodixanol on thrombus formation and fibrinolysis. Thromb Res 2003;112:65-71 CrossRef Medline

18. Dalby MC, Davidson SJ, Burman JF, et al. Systemic platelet effects of contrast media: implications of cardiologic research and clinical practice. Am Heart J 2002;143:E1 Medline

19. Markou CP, Chronos NA, Hanson SR. Antithromotic effects of ionic and non-ionic contrast media in nonhuman primates. Thromb Haemost 2001;85:488-93 Medline

20. Li X, Gabriel DA. Differences between contrast media in the inhibition of platelet activation by specific platelet agonists. Acad Radiol 1997;4:108-14 CrossRef Medline

21. NINDS t-PA Stroke Study Group. Generalized efficacy of t-PA for acute stroke: subgroup analysis of the NINDS t-PA Stroke Trial. Stroke 1997;28: 2119-25 CrossRef Medline

22. NINDS t-PA Stroke Study Group. Intracerebral hemorrhage after intravenous t-PA therapy for ischemic stroke. Stroke 1997;28: 2109-18 CrossRef Medline

23. Marcos SK, Thomsen HS, Exley CM; Members of Contrast Media Safety Committee of European Society of Urogenital Radiology (ESUR). Contrast media: interactions with other drugs and clinical tests. Eur Radiol 2005;15:1463-68 CrossRef Medline

24. Frohlich JM. Systematic survey of interactions between contrast media and other drugs. Special edition by Guerbet Switzerland; 2001

25. Corot C, Perrin JM, Belleville J, et al. Effect of iodinated contrast media on blood clotting. Invest Radiol 1989;24:390-93 CrossRef Medline

26. Ing JJ, Smith DC, Bull BS. Differing mechanisms of clotting inhibition by ionic and nonionic contrast agents. Radiology 1989;172: 345-48 CrossRef Medline

27. Kopko PM, Smith DC, Bull BS: Thrombin generation in nonclottable mixtures of blood and nonionic contrast agents. Radiology 1990;174:459-61 CrossRef Medline

28. Georgakis A, Ener RA, Jin J, et al. Risk of thrombogenicity among nonionic radiocontrast agents. J Invasive Cardiol 2008;20:349-53 Medline

29. LaBounty TM, Shah M, Raman SV, et al. Within-hospital and 30-day outcomes in 107,994 patients undergoing invasive coronary an- giography with different low-osmolar iodinated contrast media. Am J Cardiol 2012;109:1594-99 CrossRef Medline

30. Sutton AG, Ashton VJ, Campbell PG, et al. A randomized prospective trial of ioxaglate 320 (Hexabrix) vs. iodixanol 320 (Visipaque) in patients undergoing percutaneous coronary intervention. Catheter Cardiovasc Interv 2002;57:346-52 CrossRef Medline

31. Dehmer GJ, Gresalfi N, Daly D, et al. Impairment of fibrinolysis by streptokinase, urokinase and recombinant tissue-type plasminogen activator in the presence of radiographic contrast agents. J Am Coll Cardiol 1995;25:1069-75 CrossRef Medline

32. Pislaru S, Pislaru C, Szilard M, et al. In vivo effects of contrast media on coronary thrombolysis. Am Coll Cardiol 1998;32:1102-08 CrossRef

33. Van Beek EJ, Levi M, Reekers JA, et al. Increased plasma levels of PAI-1 after administration of nonionic contrast medium in patients undergoing pulmonary angiography. Radiology 1994;193: 821-23 CrossRef Medline

34. Hill V, Meunier J, Shaw GJ, et al. Effect of iodixanol on rt-PA thrombolysis in human clots. In: Proceedings of the Annual Meeting of the American Society of Neuroradiology and Neuroradiology Education and Research Foundation Symposium, Boston, Massachusetts. May 16-20, 2010

35. Dani KA, Muir KW. Do iodinated contrast agents impair fibrinolysis in acute stroke? A systematic review. AJNR Am J Neuroradiol 2010;31:170-74 CrossRef Medline

36. Franke RP, Fuhrmann R, Hiebl B, et al. Influence of various radiographic contrast media on the buckling of endothelial cells. Microvasc Res 2008;76:110-13 CrossRef Medline

37. Franke RP, Fuhrmann R, Park JW, et al. The effect of radiographic contrast media on the morphology of human venous endothelial cells. Clin Hemorheol Microcirc 2007;37:329-38 Medline

38. Aspelin P, Stacul F, Thomsen HS, et al; Members of the Contrast Media Safety Committee of the European Society of Urogenital Radiology (ESUR). Effects of iodinated contrast media on blood and endothelium. Eur Radiol 2006;16:1041-49 CrossRef Medline

39. Jung F, Mrowietz C, Rickert D, et al. The effect of radiographic contrast media on the morphology of human erythrocytes. Clin Hemorheol Microcirc 2008;38:1-11 Medline

40. Aulie Michelet A. Effects of intravascular contrast media on bloodbrain barrier: comparison between iothalamate, iohexol, iopentol, and iodixanol. Acta Radiol 1987;28:329-33 CrossRefMedline

41. Sage MR, Wilson AJ, Scroop R. Contrast media and the brain: the basis of CT and MR imaging enhancement. Neuroimaging Clin NAm 1998;8:695-707 Medline

42. Sage MR, Wilcox J, Evill CA, et al. Comparison of blood-brain barrier disruption by intracarotid iopamidol and methylglucamine iothalamate. AJNR Am J Neuroradiol 1983;4:893-95 Medline

43. Whisson CC, Wilson AJ, Evill CA, et al. The effect of intracarotid nonionic contrast media on the blood-brain barrier in acute hypertension. AJNR Am J Neuroradiol 1994;15:95-100 Medline

44. Lee KK, Kang DH, Kim YS, et al. Serious blood brain disruption after coil embolization of unruptured intracranial aneurysm: report of two cases and role of immediate postembolization CT scan. J Korean Neurosurg Soc 2011;50:45-47 CrossRef Medline

45. Ozturk A, Saatci I, Pamuk, et al. Focal increased cortical density in immediate postembolization CT scans of patients with intracranial aneurysms. AJNR Am J Neuroradiol 2006;27:1866-75 Medline

46. Hayakawa K, Morris TM, Katzberg RW. Opening of the blood-brain barrier by intravenous contrast media in euvolemic and dehydrated rabbits. Acta Radiol 1989;30:439-44 CrossRef Medline

47. Murphy A, Heran M, Smith A, et al. Intra-arterial thrombolysis and parenchymal contrast staining: determining its meaning in the setting of acute stroke intervention. In: Proceedings of the Annual Meeting of the American Society of Neuroradiology and Neuroradiology Education and Research Foundation Symposium, Vancouver, British Columbia, Canada. May 18-21, 2009:375

48. Knight RA, Barker PB, Fagan SC, et al. Prediction of impending 
hemorrhagic transformation in ischemic stroke using magnetic resonance imaging in rats. Stroke 1998;29:144-51 CrossRef Medline

49. Neumann-Haefelin C, Brinker G, Uhlenküken U, et al. Prediction of hemorrhagic transformation after thrombolytic therapy of clot embolism: an MRI investigation in rat brain. Stroke 2002;33:1392-98 CrossRef Medline

50. Hom J, Dankbaar JW, Soares BP, et al. Blood-brain barrier permeability assessed by perfusion CT predicts symptomatic hemorrhagic transformation and malignant edema in acute ischemic stroke. AJNR Am J Neuroradiol 2011;32:41-48 CrossRef Medline

51. Aviv RI, d'Esterre CD, Murphy BD, et al. Hemorrhagic transformation of ischemic stroke: prediction with CT perfusion. Radiology, 2009;250:867-77 CrossRef Medline

52. Lin K, Kazmi KS, Law M, et al. Measuring elevated microvascular permeability and predicting hemorrhagic transformation in acute ischemic stroke using first-pass dynamic perfusion CT imaging. AJNR Am J Neuroradiol, 2007;28:1292-98 CrossRef Medline

53. Kim EY, Kim SS, Na DG, et al. Sulcal hyperintensity on fluid-attenuated inversion recovery imaging in acute ischemic stroke patients treated with intra-arterial thrombolysis: iodinated contrast media as its possible cause and the association with hemorrhagic transformation. J Comput Assisted Tomogr 2005;29:264-69 CrossRef Medline

54. Hjort N, Wu O, Ashkanian M, et al. MRI detection of early blood brain barrier disruption: parenchymal enhancement predicts focal hemorrhagic transformation after thrombolysis. Stroke 2008;39: 1025-28 CrossRef Medline

55. Latour LL, Kang DW, Ezzeddine MA, et al. Early blood-brain barrier disruption in human focal brain ischemia. Ann Neurol 2004;56: 468-77 CrossRef Medline

56. Lummul N, Schulte-Altedorneburg G, Bernau C, et al. Hyperattenuated intracerebral lesions after mechanical revascularization in acute stroke. AJNR Am J Neuroradiol 2014;35:345-51 CrossRef Medline

57. Pannu N, Wiebe N, Tonelli M. Prophylaxis strategies for contrastinduced nephropathy. JAMA 2006;295:2765-79 CrossRef Medline

58. Fountaine $H$, Harnish $P$, Andrew E, et al. Safety, tolerance, and pharmacokinetics of iodixanol injection, a nonionic, isosmolar, hexaiodinated contrast agent. Acad Radiol 1996;3(suppl 3):S475-84 CrossRef Medline

59. Heinrich MC, Kuhlmann MK, Grgic A, et al. Cytotoxic effects of ionic high-osmolar, nonionic monomeric, and nonionic iso-osmolar dimeric iodinated contrast media on renal tubular cells in vitro. Radiology 2005;235:843-49 CrossRef Medline

60. Dooley M, Jarvis B. Iomeprol: a review of its use as a contrast medium. Drugs 2000;59:1169-86 CrossRef Medline

61. McClennan BL, Stolberg HO. Intravascular contrast media: ionic versus nonionic: current status. Radiol Clin North Am 1991;29: 437-54 Medline

62. Lasser EC, Lang JH. Inhibition of acetylcholinesterase by some organic contrast media: a preliminary communication. Invest Radiol 1966;2:237-42

63. Gertz EW. Thromboembolic events and non-ionic contrast. Diagn Imag 1989;11:106-09

64. Paczynski RP, He YY, Diringer, et al. Multiple-dose mannitol reduces brain water content in a rat model of cortical infarction. Stroke 1997;28:1437-43; discussion 1444 Medline

65. Wilcox J, Wilson AJ, Evill CA, et al. A comparison of blood-brain barrier disruption by intracarotid iohexol and iodixanol in the rabbit. AJNR Am J Neuroradiol 1987;8:769-72 Medline

66. Macdougall NJ, McVerry F, Baird S, et al. Iodinated contrast media and cerebral hemorrhage after intravenous thrombolysis. Stroke 2011;42:2170-74 CrossRef Medline

67. Khatri P, Broderick JP, Khoury JC, et al; IMS I and II Investigators. Microcatheter contrast injections during intra-arterial thrombolysis may increase intracranial hemorrhage risk. Stroke 2008;39: 3283-87 CrossRef Medline

68. Leong S, Fanning NF. Persistent neurological deficit from iodinated contrast encephalopathy following intracranial aneurysm coiling: a case report and review of the literature. Interv Neuroradiol 2012; 18:33-41 Medline

69. Wilcox J, Sage MR. Is viscosity important in the production of blood-brain barrier disruption by intracarotid contrast media? Neuroradiology 1984;26:511-13 CrossRef Medline

70. Sood R, Taheri S, Estrada EY, et al. Quantitative evaluation of the effect of propylene glycol on BBB permeability. J Magn Reson Imaging 2007;25:39-47 CrossRef Medline

71. Jacobsen PB, Larsen A, Konarboland R, et al. Biotransformation of nonionic $\mathrm{x}$-ray contrast agents in vivo and in vitro. Drug Metab Dispos 1999;27:1205-13 Medline

72. Spencer CM, Goa KL. Iodixanol: a review of its pharmacodynamic and pharmacokinetic properties and diagnostic use as an $\mathrm{x}$-ray contrast medium. Drugs 1996;52:899-927 CrossRef Medline

73. Molina CA, Montaner J, Abilleira S, et al. Timing of spontaneous recanalization and risk of hemorrhagic transformation in acute cardioembolic stroke. Stroke 2001;32:1079-84 CrossRef Medline

74. Simard JM, Kent TA, Chen M, et al. Brain oedema in focal ischaemia: molecular pathophysiology and theoretical implications. Lancet Neurol 2007;6:258-68 CrossRef Medline

75. Zador Z, Stiver S, Wang V, et al. Role of aquaporin-4 in cerebral edema and stroke. Handb Exp Pharmacol 2009:159-70 CrossRef Medline

76. Lu A, Clark JF, Broderick JP, et al. Mechanical reperfusion is associated with post-ischemic hemorrhage in rat brain. Exp Neurol 2009; 216:407-12 CrossRef Medline

77. Dirnagl U, Lindauer U, Them A, et al. Global cerebral ischemia in the rat: online monitoring of oxygen free radical production using chemiluminescence in vivo. $J$ Cereb Blood Flow Metab 1995;15: 929-40 CrossRef Medline

78. Kumura E, Yoshimine T, Iwatsuki KI, et al. Generation of nitric oxide and superoxide during reperfusion after focal cerebral ischemia in rats. Am J Physiol 1996;270(3 pt 1):C748-52 Medline

79. Lu A, Clark JF, Broderick JP, et al. Reperfusion activates metalloproteinases that contribute to neurovascular injury. Exp Neurol 2008; 210:549-59 CrossRef Medline

80. Rosell A, Foerch C, Murata Y, et al. Mechanisms and markers for hemorrhagic transformation after stroke. Acta Neurochir Suppl 2008;105:173-78 CrossRef Medline

81. Schwartz D, Blum M, Peer G, et al. Role of nitric oxide (EDRF) in radiocontrast acute renal failure in rats. Am J Physiol 1994;267: F374-79 Medline

82. Heyman SN, Goldfarb M, Carmeli F, et al. Effect of radiocontrast agents on intrarenal nitric oxide (NO) and NO synthase activity. Exp Nephrol 1998;6:557-62 CrossRef Medline

83. Treitl M, Rupprecht $\mathrm{H}$, Wirth $\mathrm{S}$, et al. Assessment of renal vasoconstriction in vivo after intra-arterial administration of the isosmotic contrast medium iodixanol compared to the low-osmolar contrast medium iopamidol. Nephrol Dial Transplant 2009;24:1478-85 CrossRef Medline

84. Morris TW, Ekholm SE, Prentice L, et al. Iotrol, iodixanol, and 2-deoxy-D-glucose effects on neural tissue $\mathrm{CO} 2$ production. AJNR Am J Neuroradiol 1989;10:1123-26 Medline

85. Kim SJ, Salem MR, Joseph NJ, et al. Contrast media adversely affect oxyhemoglobin dissociation. Anesth Analg 1990;71:73-76 Medline

86. Uchiyama Y, Abe T, Tanaka N, et al. Factors contributing to bloodbrain barrier disruption following intracarotid injection of nonionic iodinated contrast media for cerebral angiography: experimental study in rabbits. Radiat Med 2006;24:321-26 CrossRef Medline

87. Khatri R, Khatri P, Khoury J, et al. Microcatheter contrast injections during intra-arterial thrombolysis increase intracranial hemorrhage risk. J Neurointerv Surg 2010;2:115-19 CrossRef Medline

88. Al-Ali F, Elias JJ, Tomsick TA, et al; IMS Study Groups. Relative influence of capillary index score, revascularization, and time on stroke outcomes from the Interventional Management of Stroke III Trial. Stroke 2015;46:1590-94 CrossRef Medline 